\title{
ANALISIS KEGIATAN OUTBOND TK DAN SD DI KUNINGAN
}

\author{
Agatha Kristi Pramudika Sari ${ }^{1}$, Mira Mayasarokh ${ }^{2}$ \\ Prodi PGSD STKIP Muhammadiyah Kuningan1, Prodi PGPAUD STKIP Muhammadiyah Kuningan ${ }^{2}$ \\ Email: pramudika_sari@upmk.ac.id ${ }^{1}$,Email: mira@upmk.ac.id ${ }^{2}$ \\ Sari, Agatha Kristi Pramudika. Mira Mayasarokh. (2021). Analisis Kegiatan Outbond TK dan SD di \\ Kuningan. Jurnal Pelita PAUD, 6(1), 52-57. \\ doi: https://doi.org/10.33222/pelitapaud.v6i1.1378
}

Diterima: 13-07-2021

Disetujui: 29-11-2021

Dipublikasikan: 24-12-2021

\begin{abstract}
Abstrak: Penelitian ini bertujuan untuk mendeskripsikan kegiatan outbond TK dan SD yang sering dilaksanakan di Kabupaten Kuningan. Pendekatan dalam penelitian ini menggunakan pendekatan fenomenologi yang merupakan bagian dari metode kualitatif. Teknik pengumpulan data menggunakan angket, wawancara, dan observasi. Subjek dalam penelitian ini adalah siswa, guru, dan kepala TK dan SD di Kabupaten Kuningan. Hasil penelitian menunjukkan bahwa kegiatan outbond yang dilaksanakan beberapa TK dan SD di Kabupaten Kuningan dirasa belum bisa mengembangkan potensi anak. Hal tersebut disebabkan karena beberapa faktor diantaranya, terbatasnya fasilitas outbond di area Kuningan dan sekitarnya yang children friendly, tingginya biaya yang dikeluarkan sekolah apabila ingin melakukan kegiatan outbond yang representatif. Berdasarkan hasil temuan penelitian, munculnya harapan dari sekolah-sekolah agar pengembangan fasilitas outbond yang children friendly dengan biaya terjangkau menjadi prioritas yang harus segera direalisasikan agar kegiatan dapat berjalan sesuai tujuan dari kegiatan outbond tersebut.

Kata kunci: Analisis, Outbond, TK, SD
\end{abstract}

Abstract: This study aims to describe kindergarten and elementary outbound activities that are often carried out in Kuningan Regency. The approach in this study uses a phenomenological approach which is part of a qualitative method. Data collection techniques using questionnaires, interviews, and observations. The subjects in this study were students, teachers, and principals of kindergartens and elementary schools in Kuningan Regency. The results showed that the outbound activities carried out by several kindergartens and elementary schools in Kuningan Regency were deemed unable to develop the potential of children. This is due to several factors, including limited outbound facilities in the Kuningan area and its surroundings which are child friendly, the high costs incurred by schools if they want to carry out representative outbound activities. Based on the research findings, there is hope from schools that the development of outbound facilities that are child friendly at affordable costs is a priority that must be realized immediately so that activities can run according to the objectives of the outbound activities.

Keywords: Analysis, Outbound, Kindergarten, Elementary 
P ISSN 2548-6284 E ISSN 2615-0360

Vol. 6 No. 1 Desember 2021

\section{PENDAHULUAN}

Anak-anak merupakan generasi penerus yang harus dijaga dan didukung dalam pertumbuhan dan perkembangannya. Anakanak memiliki banyak kebutuhan yang harus dipenuhi untuk mendukung proses pertumbuhan dan perkembangan. Dalam Undang-Undang No. 23 tahun 2002 (Undang-Undang Nomor 23 Tahun 2002, 2002) tentang Perlindungan Anak, terdapat pasal yang berbunyi bahwa setiap anak berhak untuk beristirahat dan memanfaatkan waktu luang, bergaul dengan anak yang sebaya, bermain, dan berkreasi sesuai dengan bakat dan minat mereka demi pengembangan diri (Mujahidatul Mukarromah, 2016). Selain itu, dalam pasal lainnya juga disebutkan bahwa anak-anak berhak mendapatkan sarana bermain yang memenuhi syarat kesehatan dan keselamatan (Thalia, 2018). Anak-anak membutuhkan sarana bermain berupa taman bermain yang layak untuk menumbuhkan dan mengembangkan potensi yang ada pada diri mereka. Pada saat ini sangat minim sekali ketersediaan ruang publik seperti taman bermain. Menurut Kak Seto dalam bulletin Tata Ruang (Ruang, 2010), konsep taman bermain anak yang bergabung dengan pusat perbelanjaan seperti yang banyak dijumpai sekarang ini belum bisa dikatakan tempat bermain yang ideal. Selain bermain di dalam ruangan, anak-anak juga diharapkan bisa bermain di luar ruangan. Hal itu dikarenakan tempat bermain di alam dengan fasilitas seperti ayunan dan sebagainya akan memberi kegembiraan dan tantangan yang lebih pada anak. Juga akan memberikan impulse pada perkembangan kecerdasan anak, baik kecerdasan fisik atau keterampilan kinestetik, sosial, dan kognitif(Permendiknas, 2018). Taman bermain tersebut selain dilengkapi fasilitas pendukung hendaknya adalah sebuah Child Friendly Space, sehingga anak merasa nyaman, aman, dan aktifitas bermain menjadi menyenangkan.

Setiap lembaga sekolah mempunyai cara dan tujuan yang berbeda dalam mengadakan kegiatan outbond untuk anak didiknya. Outbound adalah sebuah program yang dilakukan diluar ruangan maupun di alam
Analisis Kegiatan Outbond....

Agatha Kristi Pramudika Sari ', Mira Mayasarokh 2

bebas dengan berdasarkan pada prinsip belajar melalui pengalaman langsung yang disajikan dalam bentuk permainan (Muksin, 2009)

Outbound merupakan sarana penambah wawasan pengetahuan yang didapat dari serangkaian pengalaman berpetualang sehingga dapat memacu anak semangat dan kreativitas seseorang (Ancok, 2002). Sejalan dengan pendapat Ramaati outbound adalah suatu pembelajaran yang secara langsung dilakukan di alam terbuka dengan memanfaatkan alam sebagai tempat untuk belajar mengenal alam (Susanto, 2008). Selanjutnya Menurut Winarsono dalam Agustinus outbound adalah suatu kegiatan yang dilakukan oleh seseorang peserta didik untuk memantapkan pemahaman konsep pembinaan perilaku dan kepemimpinan di alam terbuka secara sistematis, terencana dan penuh kehati-hatian tanpa meninggalkan kemungkinan mengembangkan kemampuan mengambil resiko yang harus dimiliki oleh seseorang pemimpin melalui kegiatan kelompok. Menurut penelitian yang dilakukan oleh (Thalia, 2018) menyatakan bahwa outbond berpengaruh secara signifikan terhadap kecerdasan kinestetik anak AUD. Sejalan dengan penelitian yang dilakukan (Fauzan, F., \& Al Millah, 2018) yang menyatakan bahwa outbond training memiliki hubungan yang positif dan signifikan terhadap karakter kepemimpinan siswa dengan tingkat keeratan sedang atau cukup pada siswa SD. Kemampuan kinestetik anak penting untuk di kembangkan untuk memenuhi semua aspek perkembangan anak(APIT, 2012).

Berdasarkan hasil wawancara dengan Kepala TKIT Darul Amanah dan SD 'Aisyiyah di Kabupaten Kuningan, kedua lembaga yaitu lembaga TK dan SD mempunyai kesamaan waktu dan kegiatan dalam mengadakan outbond yaitu pada pertengahan semester atau biasa disebut Kegiatan Tengah Semester. Kegiatan outbond juga menjadi rutinitas tiap semester. Oleh karena itu, dalam artikel ini akan dibahas mengenai keterlaksanaan kegiatan outbond pada tingkatan pendidikan TK dan SD di Kabupaten Kuningan. Penelitian ini bertujuan untuk mendeskripsikan kegiatan outbond TK dan 
P ISSN 2548-6284 E ISSN 2615-0360

Vol. 6 No. 1 Desember 2021

SD yang sering dilaksanakan di Kabupaten Kuningan.

\section{METODE PENELITIAN}

Pendekatan dalam penelitian ini menggunakan pendekatan fenomenologi yang merupakan bagian dari metode kualitatif. Teknik pengumpulan data dilakukan secara triangulasi data melalui angket, wawancara, dan observasi. Subjek dalam penelitian ini adalah siswa, guru, dan kepala TK dan SD di Kabupaten Kuningan, dengan pertimbangan lembaga tersebut rutin mengadakan kegiatan outbond pada tengah semester di area Kuningan. Adapun TK yang dijadikan sampel yaitu TK 'Aisyiyah 1 Kuningan, TK Al-Ikhlas Cigugur, TKIT Darul Amanah. Sedangkan SD yang dijadikan sampel yaitu SD 'Aisyiyah Kuningan, SDN 1 Puncak, SDN 2 Kertawangunan. Penelitian dilaksanakan pada bulan Agustus sampai dengan Desember 2019. Teknis analisis data penelitian dilakukan melalui tahapan reduksi data, display data, dan verifikasi dan penarikan kesimpulan (Miles dan Huberman dalam (Sugiyono, 2017).

\section{HASIL DAN PEMBAHASAAN}

Berdasarkan hasil wawancara menunjukkan adanya kurangnya kesiapan dalam perencanaan kegiatan outbond, sebelum kegiatan disosialisasikan kepada siswa-siswi dan orang tuanya. Data menunjukkan, Kepala TK Al-Ikhlas Cigugur dan SD 'Aisyiyah Kuningan yang diwawancarai menyebutkan bahwa dalam perencanaan kegiatan outbond hanya berdasarkan jarak lokasi yang dekat, biaya yang murah, dan kesukaan terhadap objek favorit yang sedang popular di masyarakat. Data hasil wawancara terhadap guru kelas SDN 2 Kertawangunan dan TKIT Darul Amanah, menyebutkan bahwa panitia dari sekolah hanya menunjuk satu atau dua orang guru sebagai instruktur atau pemandu kegiatan serta tidak menyiapkan peralatan yang rumit karena dirasa fasilitas yang disediakan di lokasi outbond telah cukup untuk menunjang keberlangsungan kegiatan. Adapun berdasarkan wawancara dengan siswa TK 'Aisyiyah 1 Kuningan dan SDN 2 Puncak, biasanya lokasi pilihan kegiatan outbond hanya berenang saja di tempat renang umum, atau hanya pergi memetik buah strawberry dan berkeliling tamannya saja, atau hanya pergi ke hutan kota terdekat dan sekedar makan bersama di lokasi saja, sesuai dengan kesepakatan bersama antara panitia dari sekolah dengan orang tua murid. Menurut (Sastrohadiwiryo, 2002) menyatakan bahwa tujuan utama kegiatan pelaksanaan outbond adalah melatih para peserta untuk mampu menyesuaiakan diri dengan perubahan yang ada dengan membentuk sikap profesionalisme para peserta yang didasarkan pada perubahan dan perkembangan karakter, komitmen serta kinerja yang diharapkan akan semakin lebih baik. Untuk itu, kegiatan outbond memerlukan perencanaan yang matang untuk menentukan tujuan, target, efisiensi waktu dan lokasi, peralatan, dan tim instruktur yang sesuai.

Berdasarkan hasil wawancara dengan Kepala SDN 2 Puncak dan TKIT Darul Amanah bahwa pelaksanaan kegiatan outbond biasanya hanya satu jenis kegiatan saja tergantung dari lokasi yang dikunjungi. Misalnya jika siswa pergi ke kolam renang 'A', maka kegiatan hanya berkumpul di lokasi, berdoa, briefing, kemudian langsung berenang. Jika siswa pergi ke obyek wisata 'B', maka kegiatan hanya berkumpul di lokasi, berdoa, briefing, bermain bebas (contohnya flying fox, ayunan, jungkat jungkit, dan permainan yang ada di sekitar obyek wisata). Jika siswa pergi ke hutan kota atau taman dengan jarak terdekat dengan sekolah, maka kegiatan hanya jalan santai, bernyanyi, makan bersama, kemudian berjalan kaki kembali ke sekolah. Data tersebut didukung dengan hasil wawancara dengan sejumlah guru di TK 'Aisyiyah 1 Kuningan dan SDN 2 Kertawangunan yang menyatakan bahwa kegiatan outbond yang dilakukan bagi mereka yang terpenting adalah refreshing di luar sekolah. Guru juga membutuhkan refreshing sehingga tidak mungkin menanggung beban untuk membuat permainan, simulasi, asah otak, bermain peran, maupun studi kasus. Menurut Susanta (Susanta, 2010) menyatakan bahwa manfaat outbond yaitu (1) melatih ketahanan mental dan pengendalian diri; (2) menumbuhkan empati; (3) melahirkan semangat kompetisi; (4) meningkatkan jiwa kepemimpinan; (5) melihat kelemahan orang lain bukan sebagai kendala; (6) meningkatkan kemampuan mengambil keputusan dalam situasi sulit 
P ISSN 2548-6284 E ISSN 2615-0360

Vol. 6 No. 1 Desember 2021

secara cepat dan akurat; (7) membangun rasa percaya diri; (8) meningkatkan rasa kebutuhan akan pentingnya kerja tim untuk mencapai sasaran secara optimal; (9) dapat menghilangkan jarak antara teman baru dan teman lama dan mempererat kekompakan antara teman; (10) sikap pantang menyerah dan menumbuhkan rasa percaya diri dalam diri peserta; (11) mengasah kemampuan bersosialisasi; (12) meningkatkan kemampuan mengenal diri dan orang lain. Kegiatan outbond semestinya dilakukan melalui berbagai permainan untuk membantu meningkatkan aspek perkembangan anak.

Hasil wawancara dengan siswa menyatakan bahwa anak-anak sudah cukup senang diajak keluar sekolah, jadi mereka mempunyai kesempatan untuk bebas bermain tanpa aturan yang mengikat. Namun, tidak dipungkiri oleh kepala sekolah bahwa pengalaman yang didapat oleh siswa kurang memberi inspirasi bagi siswa dalam banyak hal, misalnya dalam kerja sama, menyelesaikan masalah, atau hanya sekedar saling akrab satu sama lain. Kegiatan outbond yang biasa dilakukan tersebut dirasa bertentangan dengan hakikat dari outbond itu sendiri. Outbond adalah permainan yang dapat merefresh pikiran dan menambah kecepatan kita, di situ terdapat pula konsep-konsep, materi, dan tujuan tertentu yang harus kita lakukan dan harus dicapai (Muhammad, 2009). Data tersebut juga menunjukkan ketidaksesuaian dengan tahapan outbond yang efektif menurut (Sastrohadiwiryo, 2002) yaitu tahapan pembentukan pengalaman (experience), tahapan perenungan pengalaman, tahapan pembentukan konsep, dan tahapan pengujian konsep(Majdah, 2019).

Adapun berdasarkan hasil wawancara dengan guru dan observasi, alasan utama mengapa kegiatan outbond yang telah dilaksanakan beberapa TK dan SD di Kabupaten Kuningan dirasa belum bisa mengembangkan potensi anak. Hal tersebut disebabkan karena beberapa faktor diantaranya: 1) Terbatasnya fasilitas outbond di area Kuningan dan sekitarnya yang children friendly, 2) Tingginya biaya yang dikeluarkan sekolah apabila ingin melakukan kegiatan outbond yang representatif. Hal tersebut berdampak
Analisis Kegiatan Outbond....

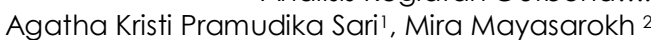

terhadap variasi kegiatan outbond yang kurang optimal, dikarenakan kurangnya fasilitas dan peralatan serta tidak adanya instruktur yang memimpin kegiatan.

Data-data hasil wawancara dan observasi tersebut didukung dengan hasil survey dalam bentuk angket dalam tabel 1 berikut:

Tabel 1. Jawaban Angket Responden

\begin{tabular}{|c|c|c|}
\hline No & Indikator & Jawaban \\
\hline 1 & $\begin{array}{l}\text { Pelaksanaan } \\
\text { outbond dalam } 1 \\
\text { tahun ajaran }\end{array}$ & $\begin{array}{l}80 \% \text { menjawab } 2 \text { kali, } \\
20 \% \text { menjawab } 1 \text { kali }\end{array}$ \\
\hline 2 & $\begin{array}{l}\text { Tujuan } \\
\text { dilaksanakan } \\
\text { outbond: }\end{array}$ & $\begin{array}{lr}80 \% & \text { menjawab } \\
\text { refreshing, } & 20 \% \\
\text { menjawab mengisi } \\
\text { jeda pasca ujian }\end{array}$ \\
\hline 3 & $\begin{array}{lr}\text { Lokasi } & \text { outbond } \\
\text { yang } & \text { biasa } \\
\text { dikunjungi } & \end{array}$ & $\begin{array}{l}50 \% \text { menjawab kolam } \\
\text { renang, } 40 \quad \% \\
\text { menjawab hutan atau } \\
\text { taman kota, } 10 \% \\
\text { menjawab lokasi } \\
\begin{array}{ll}\text { outbond yang } \\
\text { representatif }\end{array}\end{array}$ \\
\hline 4 & $\begin{array}{l}\text { Pertimbangan } \\
\text { pemilihan lokasi: }\end{array}$ & $\begin{array}{l}50 \% \text { menjawab jarak } \\
\text { dan biaya yang } \\
\text { terjangkau, } 40 \% \\
\text { menjawab } \\
\text { kesepakatan bersama } \\
\text { atas dasar suka/ tidak } \\
\text { suka dan pernah/ } \\
\text { belum pernah, } 10 \% \\
\text { menjawab tempat } \\
\text { yang representatif } \\
\text { untuk outbond }\end{array}$ \\
\hline 5 & Instruktur outbond & $\begin{array}{l}50 \% \text { menjawab guru } \\
\text { kelas, } 40 \% \text { menjawab } \\
\text { guru olah raga, } 10 \% \\
\text { menjawab tim } \\
\text { instruktur outbond }\end{array}$ \\
\hline 6 & $\begin{array}{l}\text { Variasi kegiatan } \\
\text { dalam pelaksanaan } \\
\text { kegiatan outbond: }\end{array}$ & $\begin{array}{l}60 \% \text { menjawab hanya } \\
\text { satu kegiatan saja, } \\
30 \% \text { menjawab terdiri } \\
\text { dari } 2 \text { sampai } \\
\text { kegiatan, } \\
\text { menjawab bervariasi } \\
\text { disesuaikan dengan } \\
\text { tahapan outbond }\end{array}$ \\
\hline 7 & $\begin{array}{l}\text { Ketersediaan lokasi } \\
\text { outbond yang } \\
\text { representatif } \\
\text { lingkup } \\
\text { kabupaten/kota: }\end{array}$ & $\begin{array}{lr}90 \% & \text { menjawab } \\
\text { terbatas, } & 10 \% \\
\text { menjawab lengkap }\end{array}$ \\
\hline 8 & $\begin{array}{l}\text { Biaya yang harus } \\
\text { dikeluarkan }\end{array}$ & $\begin{array}{r}\text { menjawab } \\
10 \% \\
\end{array}$ \\
\hline
\end{tabular}


P ISSN 2548-6284 E ISSN 2615-0360

Vol. 6 No. 1 Desember 2021

sekolah apabila menjawab sedang.

ingin melakukan

outbond di lokasi

yang representatif:

Mayoritas TK dan SD pada intinya dalam mengadakan outbond belum sesuai dengan makna outbond yang sebenarnya. Kesalahpahaman masyarakat akan makna outbond ini disebabkan oleh semakin maraknya penyelenggara kegiatan atau permaianan yang mengatasnamakan kegiatan outbound. Sebagai contoh, di setiap acara outbond yang diadakan TK dan SD ada yang hanya berenang di kolam renang terdekat saja atau pergi ke suatu tempat yang menyediakan permainan flying fox saja atau salah satu alat permainan outbound. Namun kegiatan tersebut tanpa dipertimbangkan esensi dari outbond yang sesungguhnya Berdasarkan kegiatan yang diikuti, maka siswa maupun orang tua siswa mendapat pemahaman bahwa outbound itu hanya sekedar satu permainan saja atau sekedar refreshing yang berdampak pada kesalahpahaman masyarakat terhadap makna dari outbond. Ketidaksesuaian kegiatan yang diadakan oleh TK dan SD tersebut, salah satunya karena keterbatasan arena outbond yang children friendly dengan biaya terjangkau yang ditunjang dengan transportasi yang mudah. Berdasarkan hasil wawancara dengan 6 orang Kepala Sekolah menyatakan harapan agar pengembangan fasilitas outbond yang children friendly dengan biaya terjangkau menjadi prioritas yang harus segera direalisasikan agar kegiatan dapat berjalan sesuai tujuan dari kegiatan outbond tersebut. Taman bermain tersebut selain dilengkapi fasilitas pendukung hendaknya adalah sebuah Child Friendly Space, sehingga anak merasa nyaman, aman, dan aktifitas bermain menjadi menyenangkan.

Setiap lembaga sekolah mempunyai cara dan tujuan yang berbeda dalam mengadakan kegiatan outbond untuk anak didiknya. Anak belajar dengan lingkungan sosial juga melalui kegiatan outbond, seperti yang diungkapakan oleh teori bandura bahwa anak belajar melalui lingkungan sosialnya (Albert, 1977). Outbound adalah sebuah program yang dilakukan diluar ruangan maupun di alam bebas dengan berdasarkan pada prinsip belajar melalui pengalaman langsung yang disajikan dalam bentuk permainan (Muksin, 2009).
Pentingnya mengembangkan kegiatan belajar anak melalui bermain, akan meningkatkan kemampuan anak dalam semua aspek perkembangan anak(Santrock, 2007), kegiatan pembelajaran yang menyenangkan akan meningkatkan kebahagaan anak sehingga aspek perkembangan anak dengan mudah tersttimulasi.

Outbond adalah kegiatan yang menyenangkan dan penuh tantangan. Bentuk kegiatannya berupa simulasi kehidupan melalui permainan-permainan (games) yang kreatif, rekreatif, dan edukatif, baik secara individual maupun kelompok dengan tujuan untuk pengembangan diri (personal development) maupun kelompok (team development). Oleh karena itu, TK dan SD yang menyelenggarakan outbound harus benarbenar memahami makna dari outbound sehingga bisa memberikan pemahaman yang benar kepada masyarakat.

\section{SIMPULAN}

Berdasarkan hasil penelitian dapat disimpulkan bahwa kegiatan outbond yang dilaksanakan beberapa TK dan SD di Kabupaten Kuningan dirasa belum bisa mengembangkan potensi anak. Hal tersebut disebabkan karena beberapa faktor diantaranya terbatasnya fasilitas outbond di area Kuningan dan sekitarnya yang children friendly, tingginya biaya yang dikeluarkan sekolah apabila ingin melakukan kegiatan outbond yang representatif. Berdasarkan hasil temuan penelitian, munculnya harapan dari sekolah-sekolah agar pengembangan fasilitas outbond yang children friendly dengan biaya terjangkau menjadi prioritas yang harus segera direalisasikan agar kegiatan dapat berjalan sesuai tujuan dari kegiatan outbond tersebut. 


\section{DAFTAR PUSTAKA}

Albert, B. (1977). Social Learning Theory. Prentice-Hall, Inc.

Ancok. (2002). Outbound management training: Aplikasi ilmu perilaku dalam pengembangan sumber daya manusia. ULL Press.

APIT, W. T. (2012). Meningkatkan Kecerdasan Kinestetik Melalui Metode Bermain Menangkap Bola Kecil Pada Kelompok a Tk Pertiwi Luwuk Kabupaten Banggai. Jurnal Teknologi Pendidikan, 1(2). https://doi.org/10.32832/tek.pend.v1i2.425

Fauzan, F., \& Al Millah, A. A. (2018). Hubungan Antara Metode Outbound Training dengan Pembentukan Karakter Kepemimpinan Siswa Kelas V di SD Sekolah Alam Bintaro. Al Ibtida: Jurnal Pendidikan Guru MI, 5(1), 53-68.

Majdah, K. (2019). Upaya Meningkatkan Kecerdasan Kinestetik Anak Usia Dini Melalui Kegiatan Menari Pada Kelompok B di RA Al-Ikhlas Medan. KINDERGARTEN: Journal of Islamic Early Childhood Education, 2(2), 92. https://doi.org/10.24014/kjiece.v2i2.9102

Muhammad, A. A. (2009). The power of outbound training. Yogyakarta: Power Books (IHDINA).
Agatha Kristi Pramudika Sari', Mira Mayasarokh 2

Mujahidatul Mukarromah

(2016). MENINGKATKAN KECERDASAN KINESTETIK ANAK USIA 5-6 TAHUN MELALUI PEMBELAJARAN TARI KREASI DI PAUD AL-JIHAD. Journal of Chemical Information and Modeling, 53(9), 1689-1699.

Muksin. (2009). Outbound For Kids. Cosmic Books.

Permendiknas. (2018). Perkembangan Kinestetik Anak Usia 5-6 tahun (p. No. 58).

Ruang, T. (2010). No TitleMendambakan Kota Layak Anak.

Santrock, J. W. (2007). Child Development (8th ed.). McGraw-Hill.

Sastrohadiwiryo, B. S. (2002). Manajemen tenaga kerja indonesia: pendekatan administratif dan operasional.

Sugiyono. (2017). Metode Penelitian Kuantitatif, Kualitatif, dan $R \& D$. Bandung: Alfabeta.

Susanta, A. (2010). Outbound Profesional. Yogyakarta: ANDI Yogyakarta.

Susanto. (2008). Merancang Outbound Training Professional. Andi Offset.

Thalia. (2018). Pengaruh Permainan Outbound Terhadap kecerdasan Kinestetik Anak Pada Kelompok B Di Bandar Klippa. RAUDHAH.

Undang-Undang Nomor 23 Tahun 2002. (2002). Perlindungan Anak. 